\title{
Improvement of a boiler feedwater system using six sigma analysis
}

\begin{abstract}
Industrial boiler systems are used in manufacturing plant to generate steam for the purpose of production. The current boiler feed exhibits the feedwater chemical parameters that are not consistent with the acceptable water chemistry limits. Around $60 \%$ of damages of power plant equipment occur due to deviation from the normal water chemistry. The Six Sigma DMAIC method was used to investigate and prioritize the main issues revolving around these parameters-namely Define-Measure-Analyze-Improve-Control. Based on this case study of the plant, it was found that the leading issues are that there is insufficient pretreatment to remove silica. It was found that there has been significant improvement to water quality to almost all the investigated parameters namely the Silica content, Hardness content and Palkalinity in the water. The results of this study have proven that Six Sigma is useful in creating sustainable improvement in process in an organization.
\end{abstract}

Keyword: Boiler systems; Six sigma; Total Quality Management (TQM) 